\title{
Surgical Aptitude Testing among Ophthalmology Residency Applicants: Current Utilization and Residency Program Directors' Perspectives
}

\author{
Amy Lu, PhD ${ }^{1}$ Samuel Beckstead, DO ${ }^{1}$ Michael Wilkinson, MD ${ }^{1}$ Ingrid U. Scott, MD MPH ${ }^{1,2}$ \\ ${ }^{1}$ Department of Ophthalmology, Penn State College of Medicine, \\ Hershey, Pennsylvania \\ 2 Department of Public Health Sciences, Penn State College of \\ Medicine, Hershey, Pennsylvania \\ Address for correspondence Ingrid U. Scott, MD, MPH, Departments \\ of Ophthalmology and Public Health Sciences, Penn State College of \\ Medicine, 500 University Drive, HU19, Hershey, PA 17033-0850 \\ (e-mail: iscott@pennstatehealth.psu.edu).
}

J Acad Ophthalmol 2019;11:e10-e17.

\begin{abstract}
Purpose To investigate the proportion of United States ophthalmology residency programs that utilize surgical aptitude testing during the applicant interview, and the perspectives of program directors (PDs) regarding surgical aptitude testing of applicants. Design This is a cross-sectional survey.

Methods An anonymous survey constructed on REDCap was emailed to the PD of each ophthalmology residency accredited by the Accreditation Council for Graduate Medical Education. Main outcome measures are proportion of programs which include surgical aptitude testing during the applicant interview, and proportion of PDs who (1) believe the current residency application process adequately assesses applicants' surgical aptitude; (2) believe surgical aptitude testing results predict surgical success; and (3) favor inclusion of surgical aptitude testing for applicant evaluation.

Results Of 115 PDs, 63 completed the survey (54.8\%). One (1.6\%) reported current use of surgical aptitude testing during the interview and $6(9.5 \%)$ used such testing previously. Fifty-five (87.3\%) respondents do not believe the residency application process adequately assesses surgical aptitude. Most respondents (40/63, 63.5\%) do not support using results

Keywords

- resident selection

- surgical aptitude

- dexterity

- stereoacuity

- interview testing

- milestones

- competencies from currently available surgical aptitude testing strategies performed during the interview to rank applicants; 47 (74.6\%) do not believe results of such testing predict ultimate surgical potential. However, 35 (55.6\%) would use surgical aptitude data for applicant screening if valid testing could be performed before the interview.

Conclusion While most PDs do not believe the current ophthalmology residency application process adequately assesses surgical aptitude, screening for surgical aptitude during the application process is seldom employed, largely due to a perceived lack of valid testing strategies available.
\end{abstract}

The United States Accreditation Council for Graduate Medical Education (ACGME) and the American Board of Ophthalmology (ABO) have identified surgical competency as an important milestone during residency as well as a fundamental

(1D)Amy Lu's ORCID is https://orcid.org/0000-0001-6872-9808. educational outcome for residency training completion. While many surgical specialties employ microscopic techniques to improve surgical outcomes and broaden the scope of practice, ophthalmology is unique in that it is one of few surgical specialties in which the majority of procedures are performed under a microscope. The small operative area in Tel: +1(212) 584-4662.

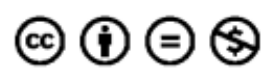

Copyright $\odot 2019$ by Thieme Medical Publishers, Inc., 333 Seventh Avenue, New York, NY 10001, USA.

License terms

10.1055/s-0039-1693419. accepted after revision

May 28, 2019 ISSN 2475-4757.

DOI https://doi.org/ ISSN 2475-4757. 
and around the eye, as well as the necessity of microscope assistance, render manual dexterity, spatial awareness, and fine motor coordination important factors in surgical outcome. Poor hand-eye coordination was the most commonly cited reason for trouble mastering surgical skills among ophthalmology residents who struggled with surgical competency. ${ }^{1}$

Despite the impact of these factors on surgical training and competency, the process of ophthalmology residency selection at most programs lacks assessment of applicants' surgical aptitude. ${ }^{2}$ Several tests for applicants' surgical aptitude have been investigated in other surgical fields including orthopedics, neurosurgery, general surgery, otolaryngology, and vascular surgery. ${ }^{3-6}$ These have yielded variable results, which may be due, in part, to lack of direct correlation between the task tested and the specific surgical techniques required for the specialty. Manual dexterity has been studied as a predictive tool for surgical training success in ophthalmology but no significant correlation between dexterity testing results and faculty evaluations of residents' surgical skills was demonstrated. ${ }^{7}$ Testing ophthalmology residency applicants' stereopsis has been proposed because reduced stereopsis has been correlated with inferior simulated surgical outcomes in individuals with no microscopic surgical experience. ${ }^{8,9}$ To our knowledge, and based on a search of the PubMed literature database, the degree of support among program directors (PDs) of ACGME-accredited ophthalmology residency programs for surgical aptitude testing as a criterion for residency applicant evaluation has not been studied previously.

The purpose of the current study is to investigate the proportion of ophthalmology residency programs in the United States that utilize surgical aptitude testing during the applicant interview, and the proportion of PDs who (1) believe the current residency application process adequately assesses applicants' surgical aptitude; (2) believe surgical aptitude testing results predict surgical success; and (3) favor inclusion of surgical aptitude testing for applicant evaluation.

\section{Methods}

The study was granted an exemption by the Institutional Review Board of the Penn State College of Medicine. An email containing a description of the study, an invitation to participate in the study, and a secure link to the survey was sent to the PD of each of the 115 ACGME-accredited ophthalmology residency programs in the United States, as identified using the ACGME/ABO list serve database (www. acgme.org) in Spring 2018. The survey was constructed using the secure online application REDCap ${ }^{10}$ hosted at the Penn State College of Medicine. Responses were collected automatically and managed under a deidentified record number generated by REDCap. Reminder emails were sent to nonresponding PDs weekly for 3 weeks.

The 21-item survey was composed of binary and multiple-choice questions. Demographic information including years in practice, years as PD, and ophthalmology subspecialty was also collected. Data were analyzed and graphed using Microsoft Excel (Microsoft, Redmond, Washington). GraphPad Prism 5 (Graphpad Software, San Diego, California) was used to perform Wilcoxon rank sum tests for comparisons among groups of data, with the statistical significance level set at $p<0.05$.

\section{Results}

Of the 115 PDs, 63 completed the survey (54.8\%). The respondents' average time in practice was $15.4 \pm 9.5$ years (median, 13 years), with a mean time as PD of $7.2 \pm 6.6$ years (median, 5 years). The most frequently represented subspecialties among PDs were glaucoma (14, 22.2\%), cornea (12, 19.0\%), and comprehensive $(11,17.5 \%)$ (-Fig. 1). None of the

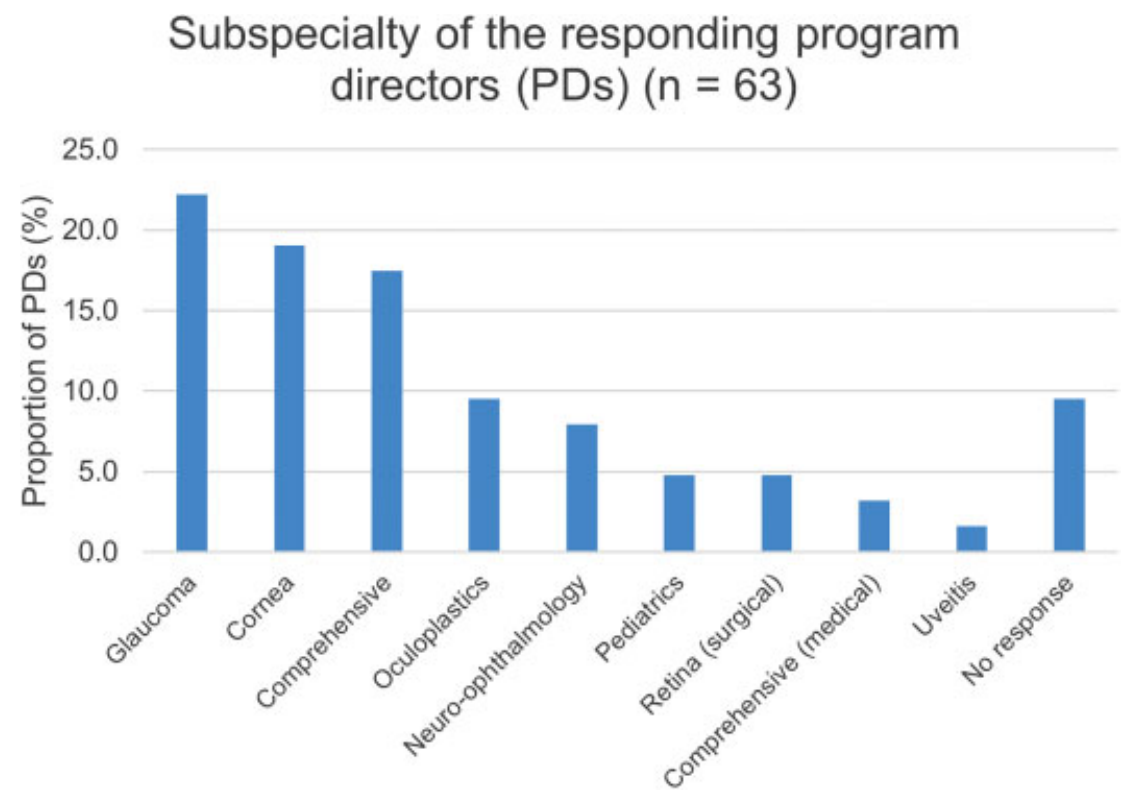

Fig. 1 Subspecialty of the responding program directors (PDs). Proportion of PDs in each subspecialty. 
e12 Surgical Aptitude Testing among Ophthalmology Residency Applicants Lu et al.

respondents specialized in medical retina, ocular oncology, or ophthalmic pathology. The majority of respondents were unfamiliar with current methods for surgical aptitude testing, with 2 (3.2\%), 20 (31.7\%), 39 (61.9\%), and 2 (3.2\%) characterizing their familiarity as very familiar, somewhat familiar, unfamiliar, or unsure, respectively.

The PD of one (1.6\%) program reported that surgical aptitude testing (in this case, manual dexterity testing) is currently a part of the program's residency applicant interview, and 6 (9.5\%) PDs reported that some form of surgical aptitude testing (manual dexterity in 4 cases, fine motor skill in 3 , and visual spatial testing in 1) had been part of the residency applicant interview previously (-Table $\mathbf{1}$ ). Reported reasons for discontinuing surgical aptitude testing were that testing was "not indicative of an applicant's ultimate surgical potential" (3 PDs) and that "testing may deter applicants from choosing to interview with or rank your program highly" (3 PDs).

The majority of respondents do not believe that results of surgical aptitude testing on interview day should be considered when ranking applicants $(40,63.5 \%)$. Similarly, most respondents do not believe that results of current surgical aptitude testing strategies correlate with such measures of applicants' surgical success as ultimate surgical potential $(47,74.6 \%)$, rate of surgical skills development $(37,58.7 \%)$, or teachability $(40,63.5 \%) ; 31(49.2 \%)$ respondents do not believe that current testing would correlate with any of these measures.

We next investigated whether the responses of the PDs were influenced by their personal training experiences and career choices; that is, whether PDs in subspecialties that involve predominantly medical management have different perspectives on the role of surgical aptitude testing compared with those in subspecialties that utilize surgical or combined medical and surgical interventions. Responses regarding consideration of surgical aptitude testing results for applicant ranking and whether such testing results correlate with ultimate surgical potential, rate of development of surgical skills, or teachability were not significantly associated with PDs' number of years in practice nor subspecialty.

If valid surgical aptitude testing were available and results of such testing could be included in the residency application, most respondents $(35,55.6 \%)$ reported they would use this information when deciding which applicants to invite for interviews and when constructing the rank list (-Table 2). Similarly, the majority of respondents $(52,82.5 \%)$ supported the use of surgical aptitude testing during medical school for the purpose of specialty selection counseling. Thus, PDs perceive a substantial difference between currently available surgical aptitude testing strategies and a validated surgical aptitude testing strategy implemented prior to the interview with respect to utility of surgical aptitude testing results for ranking applicants (current testing: mean $0.355 \pm 0.482$, median 0.0; valid testing: mean $0.574 \pm 0.499$, median 1.0 ; $p=0.016$ between medians; where $0=$ will not use, $1=$ will use). Among PDs who believed that validated surgical aptitude testing results would be useful, 19 (54.3\%) believe such information could be indicative of ultimate surgical potential and 19 (54.3\%) would use such testing results to distinguish among highly qualified applicants. Among the 26 PDs (41.3\%) who

Table 1 Surgical aptitude tests used and reasons for cessation

\begin{tabular}{|l|l|l|l|l|}
\hline & Yes & & & No \\
\hline & & Type of testing, if yes & & $62(98.4 \%)$ \\
\hline $\begin{array}{l}\text { Currently test } \\
\text { during interview? }\end{array}$ & $1(1.6 \%)$ & & & \\
\hline & & Manual dexterity & $1(100.0 \%)$ & $57(90.5 \%)$ \\
\hline $\begin{array}{l}\text { Previously tested } \\
\text { during interview? }\end{array}$ & $6(9.5 \%)$ & & & \\
\hline & & Type of testing, if yes & & \\
\hline & & Visual spatial & $1(16.7 \%)$ & \\
\hline & & Manual dexterity & $4(75.0 \%)$ & \\
\hline & & Fine motor & $3(50.0 \%)$ & \\
\hline & & Reason for cessation & & \\
\hline & & $\begin{array}{l}\text { Not indicative of ultimate surgical } \\
\text { potential }\end{array}$ & $3(50.0 \%)$ & \\
\hline & & $\begin{array}{l}\text { Not indicative of rate of surgical } \\
\text { skills development }\end{array}$ & $2(33.3 \%)$ & \\
\hline & Not indicative of teachability & $2(33.3 \%)$ & \\
\hline & & $\begin{array}{l}\text { Deters applicants from inter- } \\
\text { viewing at/ranking program }\end{array}$ & $3(50.0 \%)$ & \\
\hline & Legal concerns & $1(16.7 \%)$ & $1(16.7 \%)$ & \\
\hline & & Other & & \\
\hline & & & &
\end{tabular}


Table 2 Situation-specific reasons for and against surgical aptitude testing

\begin{tabular}{|c|c|c|c|}
\hline & Yes & & No \\
\hline $\begin{array}{l}\text { Use results of valid testing prior to interview for } \\
\text { ranking? }(n=63)\end{array}$ & $35(55.6 \%)$ & & $26(41.3 \%)$ \\
\hline Indicative of surgical success ${ }^{a}$ & $26(74.3 \%)$ & $\begin{array}{l}\text { Not indicative of surgical } \\
\text { success }\end{array}$ & $22(84.6 \%)$ \\
\hline Indicative of ultimate surgical potential & $19(54.3 \%)$ & $\begin{array}{l}\text { Not indicative of ultimate } \\
\text { surgical potential }\end{array}$ & $21(80.8 \%)$ \\
\hline Indicative of rate of surgical skills development & $15(44.1 \%)$ & $\begin{array}{l}\text { Not indicative of rate of } \\
\text { surgical skills development }\end{array}$ & $10(38.5 \%)$ \\
\hline Indicative of teachability & $16(47.1 \%)$ & $\begin{array}{l}\text { Not indicative of } \\
\text { teachability }\end{array}$ & $12(46.2 \%)$ \\
\hline Filter (attract/deter) applicants & $13(38.2 \%)$ & $\begin{array}{l}\text { Deter applicants from } \\
\text { interviewing }\end{array}$ & $5(19.2 \%)$ \\
\hline Distinguish among qualified applicants & $19(54.3 \%)$ & Legal concerns & $10(38.5 \%)$ \\
\hline Other & $0(0.0 \%)$ & Other & $1(3.8 \%)$ \\
\hline Unsure & $0(0.0 \%)$ & Unsure & $1(3.8 \%)$ \\
\hline Is current screening adequate? $(n=63)$ & $8(12.7 \%)$ & & $55(87.3 \%)$ \\
\hline $\begin{array}{l}\text { Currently perform surgical aptitude testing on } \\
\text { interview day }\end{array}$ & $1(12.5 \%)$ & $\begin{array}{l}\text { No need, all applicants } \\
\text { can achieve surgical } \\
\text { competency during } \\
\text { residency }\end{array}$ & $12(21.8 \%)$ \\
\hline Indirect measures (i.e., letters, grades) & $3(37.5 \%)$ & No valid testing & $31(56.4 \%)$ \\
\hline $\begin{array}{l}\text { No need, all applicants can achieve mastery of } \\
\text { surgical skills during residency training }\end{array}$ & $3(37.5 \%)$ & Not logistically feasible & $19(34.5 \%)$ \\
\hline \multirow[t]{2}{*}{ Other } & $1(12.5 \%)$ & Legal concerns & $21(38.2 \%)$ \\
\hline & & Other & $5(9.1 \%)$ \\
\hline $\begin{array}{l}\text { Should applicants be notified prior to testing? } \\
(n=63)\end{array}$ & $55(87.3 \%)$ & & $6(9.5 \%)$ \\
\hline Applicants can prepare differently & $30(54.5 \%)$ & $\begin{array}{l}\text { Prevent applicants from } \\
\text { preparing differently }\end{array}$ & $3(50.0 \%)$ \\
\hline Avoid surprise testing & $40(72.7 \%)$ & Prevent prior practice & $0(0.0 \%)$ \\
\hline Applicants can practice & $18(32.7 \%)$ & $\begin{array}{l}\text { Avoid increasing } \\
\text { pre-interview stress }\end{array}$ & $1(16.7 \%)$ \\
\hline Courtesy to the applicants & $43(78.2 \%)$ & $\begin{array}{l}\text { Avoid deterring applicants } \\
\text { from interviewing }\end{array}$ & $1(16.7 \%)$ \\
\hline Other & $2(3.6 \%)$ & Other & $2(33.3 \%)$ \\
\hline $\begin{array}{l}\text { Useful in retrospect with residents who had } \\
\text { difficulty? }(n=49)\end{array}$ & $29(59.2 \%)$ & & $20(40.8 \%)$ \\
\hline $\begin{array}{l}\text { Arrange to alter curriculum to ensure resident } \\
\text { success }\end{array}$ & $8(27.6 \%)$ & $\begin{array}{l}\text { Would have selected the } \\
\text { individual regardless }\end{array}$ & $11(61.1 \%)$ \\
\hline $\begin{array}{l}\text { Counsel resident on fellowship/subspecialty } \\
\text { selection }\end{array}$ & $10(34.5 \%)$ & $\begin{array}{l}\text { There are non-surgical } \\
\text { careers in ophthalmology }\end{array}$ & $5(27.8 \%)$ \\
\hline In the original ranking process & $9(31.0 \%)$ & Other & $5(27.8 \%)$ \\
\hline Other & $0(0.0 \%)$ & & \\
\hline
\end{tabular}

would not use the testing results, the most commonly cited reason is their belief that such testing results are not indicative of ultimate surgical potential $(21,80.8 \%)$.

Despite the small proportion of programs that use or have used surgical aptitude testing to evaluate applicants, 55 of the 63 respondents $(87.3 \%)$ believe that the current system for evaluating residency applicants does not adequately screen applicants' ability to achieve surgical competency. Among these, 31 (56.4\%) attribute this to lack of valid testing strategies available, 21 (38.2\%) to legal concerns, and 19 (34.5\%) to logistics and feasibility of testing on the interview day. Twelve (21.8\%) respondents believe that such testing is unnecessary because all applicants will be able to achieve surgical competency during residency training. 
Most respondents $(55,87.3 \%)$ believe that applicants should be notified in advance if surgical aptitude testing will be performed during the interview day, with "courtesy to applicants" being the most commonly reported reason for doing so $(43,78.2 \%)$ (-Table 2). The most common reason given among the 6 PDs who do not support notifying the applicant in advance is so "applicants will not prepare differently for the interview" (3,50\%).

Forty-nine respondents $(77.8 \%)$ reported that, over the past 10 years, one or more residents in their program had difficulty mastering surgical skills beyond reasonable expectations (-Fig. 2A). Of the PDs with residents who had difficulty, $42(85.7 \%)$ reported that "all" $(19,38.8 \%)$ or "most" $(23,46.9 \%)$ of these residents were able to overcome this hurdle during residency training ( - Fig. 2B). The majority of PDs of these programs (29 of $49,59.2 \%$ ) believe that surgical aptitude testing would have been useful during the application screening process of the residents who struggled (-Table 2). The reasons for this are relatively evenly distributed among "helpful in the original ranking process" (9, $31.0 \%$ ), "counsel resident on potential fellowship/subspecialty selection" (10,34.5\%), and "make arrangements to alter curriculum for that resident" (8, 27.6\%). Among the 20 PDs who believe surgical aptitude testing would not have been useful, the most commonly reported reason is that the program "would have selected this individual regardless" (11, 61.1\%), followed by "there are great career options within ophthalmology that do not require excellent surgical skills" $(5,27.8 \%)$. The remaining comments focused on other factors that contribute to surgical skills development and the lack of valid surgical aptitude testing strategies available.

\section{Discussion}

Surgical competency milestones comprise 2 of the 8 milestones established by the ACGME for graduation from ophthalmology residency. One survey reported that 56 of 58 responding ophthalmology residency programs had 1 or more residents who struggled with surgical skills mastery, $9 \%$ of all ophthalmology residents had this difficulty, and $12 \%$ of residents who struggled with surgical skills were asked to leave residency. ${ }^{1}$ The majority of residents who voluntarily leave ophthalmology programs transfer to a nonprocedural specialty, although this may not be related to their surgical skills. ${ }^{11}$ The current study confirms that a high proportion (77.8\%, - Fig. 2A) of programs have had residents with difficulty mastering surgical skills beyond reasonable expectations of surgical training. While the majority of PDs report that "all" or "most" of these residents were able to overcome this difficulty, a subset of residents were not able to do so (- Fig. 2B).

A potential strategy for decreasing the proportion of residents who leave ophthalmology programs due to an inability to master surgical skills is screening for surgical aptitude during the ophthalmology residency application process. Algorithms for surgical aptitude testing have been implemented for individuals seeking to enter advanced surgical training after core surgical training in the United Kingdom ${ }^{12,13}$ and have been studied in the United States in surgical fields other than ophthalmology with varying results. ${ }^{3-6}$ Vision screening has been proposed as a screening tool among applicants ${ }^{8}$ and specific testing strategies for manual dexterity and simulator use have been studied in ophthalmology residents. ${ }^{7,14,15}$ However, ophthalmology residency PDs' perspectives regarding surgical aptitude testing as part of the residency application process has not been studied previously.

The current study is the first national survey of ophthalmology residency PDs to investigate the proportion of programs that currently use surgical aptitude testing in their ophthalmology residency selection process and to study the perspectives of ophthalmology residency PDs with regard to inclusion of surgical aptitude testing for applicant evaluation. Results of this survey demonstrate that surgical aptitude testing is rarely used during the residency selection process. Programs that employed such testing previously
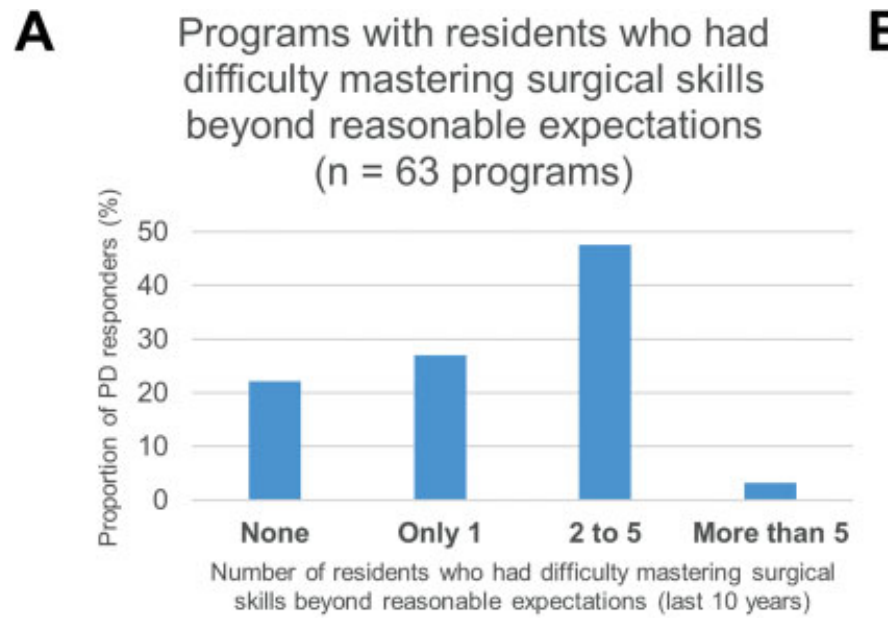

B
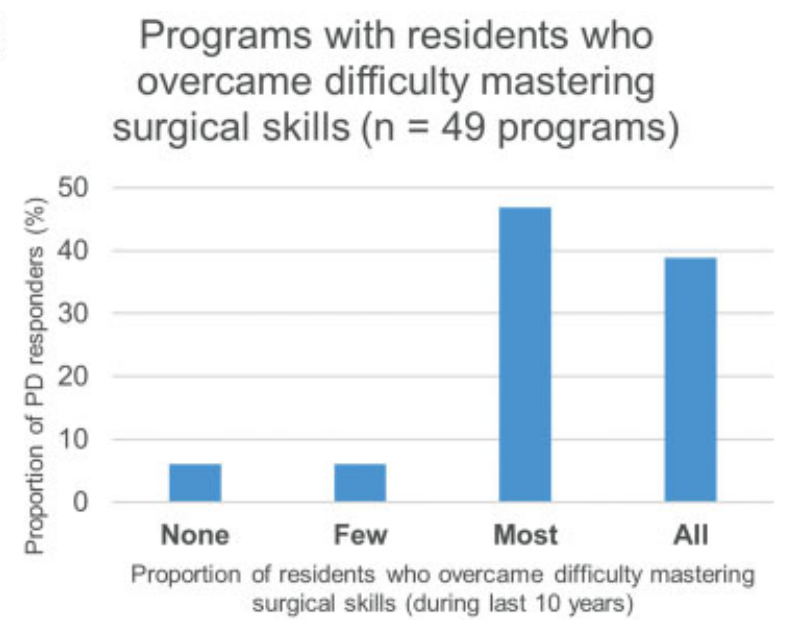

Fig. 2 Programs with residents who had difficulty mastering surgical skills beyond reasonable expectations. (A) Proportion of program director (PD) responders by number of residents, during the past 10 years, who had difficulty mastering surgical skills beyond reasonable expectations. (B) Proportion of PD responders by proportion of residents who, during the past 10 years, overcame difficulty in mastering surgical skills. 
stopped doing so, largely due to (1) a perceived lack of correlation between surgical aptitude testing results and surgical skills development and (2) the possible negative impact of such testing on applicants' ranking of programs.

Only one-third of respondents believed that results from currently available surgical aptitude testing strategies should be considered when ranking applicants. Less than half of the respondents felt that results of such tests are predictive of ultimate surgical potential, rate of progression of surgical skills, or ease of teaching surgical skills to the applicant. Despite this limited support for use of currently available surgical aptitude testing strategies, the majority of respondents $(87.3 \%)$ do not believe that the current process of residency applicant screening and evaluation adequately assesses the ability of applicants to achieve surgical competency. The low utilization of surgical aptitude testing is largely due to a perceived lack of valid surgical aptitude testing strategies currently available. The majority of respondents reported they would use the results of valid surgical aptitude testing performed prior to the interview day (i.e., included in the application package) when deciding which applicants to invite for interviews and when constructing the rank list (-Table 2). There was also support for validated surgical aptitude testing conducted by medical schools for the purpose of specialty selection counseling of medical students. This could potentially improve students' abilities to make informed decisions regarding choice of specialty and reduce the number of residents who have difficulty with attaining surgical competency. However, even validated testing strategies can yield false positives and negatives, and these results could unduly influence a student's decision to apply or not apply to a surgical specialty. Another consideration is that most trainees improve with practice (-Fig. 2B) and, therefore, surgical aptitude testing results may not be reflective. The degree to which surgical competency is teachable or attainable may vary based on the training curriculum and the learner's maturity and dedication.

Findings from this study indicate that PDs have substantial interest in understanding the baseline surgical aptitude of their applicants but are concerned about the validity and feasibility of testing. Validity testing has been performed in surgical fields outside ophthalmology with varying results and multifactorial considerations in study design. ${ }^{16,17}$ In otolaryngology, the quality of applicants' soap carvings during residency interviews did not correlate with programs' final assessments of applicants' surgical skill. ${ }^{6}$ In general surgery, there was no self-selection of surgical versus medical training by medical students based on actual surgical skill or experience with manual dexterity activities. ${ }^{18}$ However, several studies have demonstrated correlations between aptitude and speed of learning during simulation of specific procedures including laparoscopic appendectomy, endovascular skills, and z-plasty in medical students and residents. ${ }^{5,19,20}$ of note, studies of visual spatial testing revealed that residents with higher aptitude skills performed better on simulations but not ACGME milestones. ${ }^{21}$ Another consideration is that aptitude tests may have a role in predicting progression of a specific microsurgical skill set but may not be reflective of all the aspects, including nonsurgical, necessary to becoming a successful surgeon.

The aforementioned studies highlight the importance of validating aptitude tests against objective measures of surgical success that are relevant to the training process of a specific specialty and to clinical practice. In the ophthalmology literature, dexterity testing alone was unable to distinguish ophthalmology resident success as assessed by faculty evaluations; testing of multiple factors, including spatial perception and practical surgical skills, was suggested. ${ }^{7}$ Other works have shown that fine motor skills and stereoacuity affect performance on cataract surgery simulators. $^{9,22,23}$ Furthermore, results on virtual reality cataract simulators have been reported to be significantly associated with real-life cataract surgery performance. ${ }^{15,24-26}$ It is important to note that, in these studies, there were improvements in all participant groups except experienced surgeons. $^{9,24}$ This indicates that attitude toward and willingness to practice, in conjunction with inherent ability, are critical components to fully predict surgical skills development. Furthermore, because manual dexterity tests did reflect higher surgical aptitude in residents compared with the general population ${ }^{7}$ and skills gained from one simulator did not transfer to another, ${ }^{23}$ it is important to utilize a test or series of tests that are valid. In addition, it is important to consider the improved performance of participants after practice, suggesting that applicants' surgical aptitude testing results may be influenced by whether or not they have prior notification of the specific nature of the testing, which may vary based on each applicant's familiarity with the program and the timing of the interview offer.

In addition to a perceived lack of available valid surgical aptitude tests, other barriers to utilization of surgical aptitude testing during the ophthalmology residency selection process include PDs' concerns regarding potential legal ramifications (38.2\%), logistics of including such testing on the interview day (34.5\%), and perception that most applicants would be able to master surgical skills competencies during residency training such that baseline surgical aptitude testing is not necessary (21.8\%) (-Table 2 ). There was also concern that prior notification of testing would increase applicants' stress regarding the interview (16.7\%) and negatively impact applicants' opinion of the program (16.7\%). Research in general surgery and otolaryngology has shown that one to two forms of aptitude testing was acceptable to applicants and was logistically feasible during interview day. ${ }^{27}$

In terms of potential legal ramifications, applicants are protected against discrimination during the medical residency interview process on the basis of race, gender, religion, and disabilities, among others, by several federal statutes. These include Title VII of the Civil Rights Act and the Americans with Disabilities Act (ADA). ${ }^{28,29}$ The ADA grants protection to persons with an impairment that substantially limits one or more major life activities, one of which is "working." Specifically, the 2008 amendment of the ADA led to repudiation of judicial narrowing of the terms "substantially" and "major," which may qualify more medical 
trainees seeking employment that involves specific expertise. ${ }^{30}$ Poor performance on surgical aptitude tests may be due to a disability. Ranking an otherwise qualified applicant low due to poor performance on surgical aptitude tests might be considered discriminatory and individuals who have difficulty mastering surgical skills should, ideally, be provided with the extra training needed to master those skills. Most of the PD respondents in our study who had residents with difficulty mastering surgical skills beyond reasonable expectations reported that these residents were ultimately able to master those skills. The Equal Employment Opportunity Commission has stated that pre-employment inquiries which express gender discrimination is unlawful unless "based upon a bona fide occupational qualification." 31 This urges consideration of whether or not surgical aptitude testing is based upon a bona fide occupational qualification.

Study limitations include the fact that the perspectives of the 63 PDs who responded to our survey may not be representative of the perspectives of all PDs. There may also be some bias in that PDs who feel more strongly for or against surgical aptitude testing might have been more motivated to participate. Moreover, there may be some recall bias, as the PDs were asked to recall details of their program, which may be simpler for some respondents than others based on such factors such as program size and duration of the respondent's tenure at his or her program.

Overall, factors other than those measured by surgical aptitude testing are important to surgical and clinical success in ophthalmology, and most individuals who do not perform well on cataract simulator exercises are able to improve with practice. However, with the large number of qualified applicants and the ACGME requirements for surgical competency, surgical aptitude testing may be a useful tool to distinguish among applicants and/or to modify the surgical curricula as needed for those otherwise outstanding residents who may have difficulty with mastery of surgical skills.

\section{Note}

This study was presented in part at the Association for Research in Vision and Ophthalmology Annual Meeting, 2019, Vancouver British Columbia, Canada.

\section{Funding \\ None.}

\section{Conflict of Interest}

None declared.

\section{References}

1 Binenbaum G, Volpe NJ. Ophthalmology resident surgical competency: a national survey. Ophthalmology 2006;113(07):1237-1244

2 Lee AG, Golnik KC, Oetting TA, et al. Re-engineering the resident applicant selection process in ophthalmology: a literature review and recommendations for improvement. Surv Ophthalmol 2008; 53(02):164-176

3 Williams JF, Watson SL, Baker DK, et al. Psychomotor testing for orthopedic residency applicants: a pilot study. J Surg Educ 2017; 74(05):820-827
4 Roitberg B, Banerjee P, Luciano C, et al. Sensory and motor skill testing in neurosurgery applicants: a pilot study using a virtual reality haptic neurosurgical simulator. Neurosurgery 2013;73 (Suppl 1):116-121

5 Van Herzeele I, O’Donoghue KGL, Aggarwal R, Vermassen F, Darzi A, Cheshire NJW. Visuospatial and psychomotor aptitude predicts endovascular performance of inexperienced individuals on a virtual reality simulator. J Vasc Surg 2010;51(04):1035-1042

6 Tang CG, Hilsinger RL Jr, Cruz RM, Schloegel LJ, Byl FM Jr, Rasgon BM. Manual dexterity aptitude testing: a soap carving study. JAMA Otolaryngol Head Neck Surg 2014;140(03):243-249

7 Kirby TJ. Dexterity testing and residents' surgical performance. Trans Am Ophthalmol Soc 1979;77:294-307

8 Blomquist P. Is it time to adopt vision screening for ophthalmology residency program applicants? J Acad Ophthalmol. 2014;07 (01):e001-e002

9 Sachdeva R, Traboulsi EI. Performance of patients with deficient stereoacuity on the EYESi microsurgical simulator. Am J Ophthalmol 2011;151(03):427-33.e1

10 Harris PA, Taylor R, Thielke R, Payne J, Gonzalez N, Conde JG. Research electronic data capture (REDCap)-a metadata-driven methodology and workflow process for providing translational research informatics support. J Biomed Inform 2009;42(02):377-381

11 Hatton MP, Loewenstein J. Attrition from ophthalmology residency programs. Am J Ophthalmol 2004;138(05):863-864

12 Tansley P, Kakar S, Withey S, Butler P. Visuospatial and technical ability in the selection and assessment of higher surgical trainees in the London deanery. Ann R Coll Surg Engl 2007;89(06):591-595

13 Gallagher AG, Leonard G, Traynor OJ. Role and feasibility of psychomotor and dexterity testing in selection for surgical training. ANZ J Surg 2009;79(03):108-113

14 Oetting TA. Surgical competency in residents. Curr Opin Ophthalmol 2009;20(01):56-60

15 Roohipoor R, Yaseri M, Teymourpour A, Kloek C, Miller JB, Loewenstein JI. Early performance on an eye surgery simulator predicts subsequent resident surgical performance. J Surg Educ 2017;74(06):1105-1115

16 Louridas M, Szasz P, de Montbrun S, Harris KA, Grantcharov TP. Can we predict technical aptitude? A systematic review. Ann Surg 2016;263(04):673-691

17 Gardner AK, Ritter EM, Paige JT, Ahmed RA, Fernandez G, Dunkin BJ. Simulation-based selection of surgical trainees: considerations, challenges, and opportunities. J Am Coll Surg 2016;223 (03):530-536

18 Panait L, Larios JM, Brenes RA, et al. Surgical skills assessment of applicants to general surgery residency. J Surg Res 2011;170(02): 189-194

19 Buckley CE, Kavanagh DO, Gallagher TK, Conroy RM, Traynor OJ, Neary PC. Does aptitude influence the rate at which proficiency is achieved for laparoscopic appendectomy? J Am Coll Surg 2013; 217(06):1020-1027

20 Wanzel KR, Hamstra SJ, Anastakis DJ, Matsumoto ED, Cusimano MD. Effect of visual-spatial ability on learning of spatially-complex surgical skills. Lancet 2002;359(9302):230-231

21 Hinchcliff E, Green I, Destephano C, et al. Visuospatial aptitude testing differentially predicts simulated surgical skill. J Minim Invasive Gynecol 2018;25(06):1044-1050

22 Chung AT, Lenci LT, Wang K, et al. Effect of fine-motor-skill activities on surgical simulator performance. J Cataract Refract Surg 2017;43(07):915-922

23 Selvander M, Åsman P. Virtual reality cataract surgery training: learning curves and concurrent validity. Acta Ophthalmol 2012; 90(05):412-417

24 Thomsen ASS, Bach-Holm D, Kjærbo H, et al. Operating room performance improves after proficiency-based virtual reality cataract surgery training. Ophthalmology 2017;124(04):524-531

25 McCannel CA, Reed DC, Goldman DR. Ophthalmic surgery simulator training improves resident performance of 
capsulorhexis in the operating room. Ophthalmology 2013;120 (12):2456-2461

26 Thomsen ASS, Smith P, Subhi Y, et al. High correlation between performance on a virtual-reality simulator and real-life cataract surgery. Acta Ophthalmol 2017;95(03):307-311

27 Jardine D, Hoagland B, Perez A, Gessler E. Evaluation of surgical dexterity during the interview day: another factor for consideration. J Grad Med Educ 2015;7(02):234-237

28 Title VII of the Civil Rights Act of 1964, 42 USC §2000e, et.seq. Available at: https://www.eeoc.gov/laws/statutes/titlevii.cfm. Accessed April 12, 2019.
29 Americans with Disabilities Act Amendments Act of 2008, 42 USC $\S 12101$ Note. Available at: https://www.eeoc.gov/laws/statutes/ adaaa.cfm. Accessed April 12, 2019

30 Smith WT, Allen WL. Implications of the 2008 amendments to the Americans with Disabilities Act for medical education. Acad Med 2011;86(06):768-772

31 Code of Federal Regulations. 29 CFR 1604.7-pre-employment inquiries as to sex; 2009. Available at: https://www.govinfo.gov/app/ details/CFR-2009-title29-vol4/CFR-2009-title29-vol4-sec1604-7/ summary. Accessed April 12, 2019 